\title{
Geoactiva't. Establir sinergies entre nivells educatius diferents
}

\author{
Josep Padullés Cubino \\ Dolors Roset Pagès \\ Anna Ribas Palom \\ Jaume Feliu Torrent \\ Universitat de Girona. Departament de Geografia \\ josep.padulles@udg.edu \\ dolors.roset@udg.edu \\ anna.ribas@udg.edu \\ jaume.feliu@udg.edu
}

Rebut: juny de 2017

Acceptat: juny de 2017

\section{Resum}

El projecte Geoactiva't neix al Departament de Geografia de la Universitat de Girona com a eina per acostar els estudiants del grau de Geografia, Ordenació del Territori i Gestió del Medi Ambient a la tasca docent de secundària i, alhora, presentar, als alumnes d'ESO, conceptes, eines i mètodes de la geografia des d'una perspectiva experimental i dinàmica. S’organitza a partir de sis sessions, amb la col-laboració de quatre llicenciats o graduats en Geografia que han realitzat el màster en Formació del Professorat d'ESO i batxillerat. Entre els èxits assolits per aquest projecte, en destaquen la motivació per aprendre que es genera entre l'alumnat de secundària, la possibilitat que té l'alumne del grau de descobrir la tasca docent abans de realitzar els estudis de postgrau i la promoció que es fa dels estudis del grau de Geografia en l'àmbit de l'educació secundària.

Paraules clau: didàctica de la geografia; educació secundària obligatòria; ensenyamentaprenentatge; promoció de la geografia

Resumen. Geoactiva't. Establecer sinergias entre diferentes niveles educativos

El proyecto Geoactiva't nace en el Departamento de Geografía de la Universidad de Girona con el doble objetivo de, por una parte, acercar el alumnado del grado de Geografía, Ordenación del Territorio y Gestión del Medio Ambiente a las tareas docentes de secundaria y, por otra, presentar a los alumnos de secundaria conceptos, herramientas y métodos de la geografía desde una perspectiva experimental y dinámica. Se organiza a partir de seis sesiones que cuentan con la colaboración de cuatro licenciados o graduados en Geografía que han realizado el máster en Formación del Profesorado de ESO y bachillerato. Entre los logros de este proyecto, destacan la motivación para aprender que se genera entre el alumnado de secundaria, la posibilidad que tiene el estudiante de grado de descubrir la tarea docente antes de iniciar estudios de postgrado y la promoción de los estudios del grado de Geografía en el ámbito de la educación secundaria.

Palabras clave: didáctica de la geografía; educación secundaria obligatoria; enseñanzaaprendizaje; promoción de la geografía 
Résumé. Geoactiva't. Mettre en place des synergies entre différents niveaux d'éducation

Le projet Geoactiva't a été conçu dans le Département de Géographie de l'Universitat de Girona dans un double objectif : en premier lieu, faire connaître l'enseignement secondaire aux étudiants suivant la licence de Géographie, de l'Aménagement du Territoire et de Gestion de l'Environnement, et aussi, initier les élèves de l'enseignement secondaire aux concepts, outils et méthodes de la géographie dans une perspective dynamique et expérimentale. The projet est organisé autour de 6 sessions d'enseignement avec la participation de 4 géographes qui ont achevé le Master de Formation des Enseignants de l'école secondaire. Les réalisations de ce projet comprennent la motivation pour apprendre généré par le projet chez les élèves de secondaire, la possibilité offerte à l'étudiant de la Licence de Géographie de découvrir la tâche d'enseignement avant de commencer des études de troisième cycle et la promotion des études de Licence de Géographie parmi les élèves de l'enseignement secondaire.

Mots-clés: didactique de la géographie; enseignement secondaire; enseignement et apprentissage de la géographie; promotion de la géographie

\section{Abstract. Geoactiva't. Creating synergies among different levels of education}

The Geoactiva't project was designed by the Department of Geography at the University of Girona as a tool to introduce undergraduate students to secondary teaching, as well as to show secondary school students various concepts, tools and methods used in geography from an experimental and dynamic perspective. The project is organized in six different sessions with the collaboration of four graduates of the Bachelor's Degree in Geography who have completed a master program in secondary education. The major goals of the Geoactiva't project include fostering motivation for learning among secondary school students, discovering secondary teaching before reaching the post-graduate level and promoting geography studies in secondary education.

Keywords: teaching of geography; compulsory secondary education; teaching-learning; promotion of geography

\section{Sumari}

1. Contextualització 3. Resultats i valoració

2. Organització i desenvolupament Referències bibliogràfiques

\section{Contextualització}

La metodologia d'ensenyament de la geografia ha de proporcionar una formació científica i humana adaptant-la al context sociocultural i a les aptituds individuals. D'una banda, s'ha d'encaminar cap a l'adquisició de coneixement que familiaritzi l'alumnat amb la realitat del món natural i social que l'envolta i, de l'altra, vers una adquisició de pertinença a la comunitat local, regional, nacional i internacional. A més, la geografia és una disciplina transversal i integradora que esdevé essencial en l'àmbit de la docència per vincular conceptes de matèries diferents. 
Ara bé, perquè l'aprenentatge de la geografia sigui significatiu, ha d'estar contextualitzat en el temps i en l'espai, tant en l'educació secundària com terciària. Per aquest motiu, és important que l'ensenyament d'aquesta matèria es mantingui actualitzada en continguts i mètodes. A més, la vinculació de l'ensenyament de geografia entre els diferents nivells acadèmics pot ajudar a promoure una millor preparació dels futurs docents abans dels estudis de postgrau, cosa que, sens dubte, tindrà repercussió en l'educació del demà (Carretero, 1989; Delors, 1996; García Hoz, 1996).

Per afrontar aquests reptes des d'una perspectiva integradora, el Departament de Geografia de la Universitat de Girona (UdG) ha desenvolupat Geoactiva't. De forma sintètica, explicarem que aquest projecte permet que alumnes del grau en Geografia, Ordenació del Territori i Gestió del Medi Ambient (GOTiGMA) posin en pràctica diferents tallers de l'àmbit de la geografia amb alumnes de tercer curs d'educació secundària obligatòria. De forma específica, els tres objectius que s'hi plantegen són:

- Donar a conèixer conceptes, eines i mètodes de la geografia des d'una perspectiva experimental i dinàmica als estudiants dels centres de secundària de les comarques gironines.

- Oferir als universitaris del grau en GOTiGMA un primer contacte amb el món de l'ensenyament secundari com a possible sortida professional.

- Promocionar el grau en GOTiGMA entre l'alumnat d'ESO.

Geoactiva't s'inicia durant el curs acadèmic 2014-2015, en el marc de l'assignatura Tècniques i Mètodes Professionals en Geografia (TMPG; sis crèdits ECTS). L'assignatura s'imparteix de forma obligatòria durant el darrer semestre de l'últim curs del grau. És de caràcter instrumental i ha de permetre que l'alumne es doti de les tècniques i dels mètodes professionals i de recerca d'ús quotidià en geografia. A més, confereix també a l'estudiant coneixement pràctic sobre la diversitat de sortides professionals que hi ha vinculades al grau, entre les quals trobem l'activitat docent, on s'emmarca Geoactiva't.

Per tal d'aprofundir en el projecte Geoactiva't, les seccions subsegüents recullen, d'una banda, l'esquema organitzatiu i de posada en pràctica del projecte $i$, de l'altra, els resultats i les valoracions principals que se'n poden extreure.

\section{Organització i desenvolupament}

\subsection{Descripció general}

Els tallers de Geoactiva't estan dissenyats per ser portats a terme per grups de tercer d'ESO, moment en què els estudiants d'aquest curs ja tenen assolides les competències bàsiques i els continguts que els han de permetre entendre $\mathrm{i}$ assolir els objectius que persegueixen aquests tallers proposats a Geoactiva't. El plantejament del projecte s'organitza en un total de sis sessions en el marc de l'assignatura TMPG: 
- Sessió 1. Presentació del projecte a l'alumnat de grau, configuració dels equips de treball i assignació d'un centre d'ESO a cada equip.

- Sessions 2, 3 i 4. Treball a l'aula per elaborar el material didàctic.

- Sessió 5. Desenvolupament dels tallers al centre d'ESO.

- Sessió 6. Posada en comú entre l'alumnat del grau sobre el procés i les experiències viscudes en els diferents centres d'ESO.

El desenvolupament correcte requereix la participació coordinada de quatre agents clau, amb tasques específiques per a cadascun (taula 1).

Taula 1. Agents implicats en el projecte Geoactiva't i tasques desenvolupades per cadascun Agents implicats Tasques que han de realitzar

\begin{tabular}{ll}
\hline Departament de Geografia de la UdG. & - Oferir material i recursos per dur a terme el projecte. \\
& - Fer-ne partícip el professorat universitari. \\
& - Contactar amb els centres d'ESO. \\
& - Realitzar un seguiment continuat de les diferents \\
& fases del projecte. \\
\hline Alumnat del grau en GOTGMA. & - Definir les diferents activitats que caldrà dur a terme \\
& al llarg dels tallers. \\
& - Apropar les activitats al context del centre d'ESO. \\
& - Executar, en equips de cinc o sis alumnes, els tallers \\
& al centre d'ESO designat. \\
& - Acollir el projecte. \\
& - Oferir l'espai i el temps necessaris per realitzar el \\
& projecte. \\
Centres d'ESO. & - Avaluar els tallers un cop finalitzats. \\
& - Gestionar el projecte en conjunt. \\
\hline Llicenciats o graduats en Geografia & Fer un esbós dels tallers. \\
que han realitzat el màster en Formació \\
del Professorat d'ESO i Batxillerat.
\end{tabular}

Font: elaboració pròpia.

\subsection{Preparació $i$ desenvolupament de la sessió $i$ dels tallers}

Els estudiants de l'assignatura TMPG es divideixen en equips de cinc o sis membres. A cada grup, se li assigna un centre d'ESO amb el qual s'ha contactat prèviament i s'ha arribat a un acord de col-laboració. Els equips s'encarreguen de preparar una sessió completa de dues hores per a un total de 60 a 90 alumnes de tercer d'ESO (taula 2).

El cos central de la sessió gira entorn dels tres tallers que, alhora, es complementen entre si per donar una visió integradora i pràctica del coneixement 
Taula 2. Fases i característiques de la sessió didàctica preparada en el marc del projecte Geoactiva't

\begin{tabular}{lll}
\hline Fases & Durada & Descripció \\
\hline Introducció. & 15 minuts. & Presentació de l'activitat. Adreçada a tot el grup. \\
\hline Tallers. & 1 hora i 30 minuts. & $\begin{array}{l}\text { Realització de tres tallers amb subgrups de } 10 \text { a } 20 \text { alumnes. } \\
\text { Cada taller té una durada de } 30 \text { minuts i els nois i noies van } \\
\text { passant de l'un a l'altre. }\end{array}$ \\
\hline Conclusió. & 15 minuts. & $\begin{array}{l}\text { Posada en comú amb tot el grup i valoració final. Cada grup } \\
\text { explica si li ha agradat o no l'últim taller que ha realitzat i } \\
\text { per què. }\end{array}$ \\
\hline
\end{tabular}

Font: elaboració pròpia.

geogràfic. A continuació, en descrivim sintèticament les característiques i els atributs:

— Taller «Orientem»: es desenvolupa fora de l'aula. L'objectiu que persegueix és transmetre que la geografia permet elaborar la cartografia pertinent, variada i adequada per a cada situació. Això inclou, entre altres materials, mapes per orientar-nos i situar-nos arreu del món. Per dur-lo a terme, els alumnes es divideixen novament en dos grups, cadascun dels quals disposa de dos mapes en format paper (topogràfic i ortofotomapa) de l'entorn del centre, on figuren fins a tres fites. A més, cada grup disposa també d'una tauleta electrònica amb una aplicació carregada amb cartografia digital. Utilitzant tota la cartografia disponible, els grups hauran d'aconseguir passar per les tres fites, al mateix temps que enregistren el recorregut (track) per arribar-hi. Finalment, s'anima l'alumnat a reflexionar sobre l'ús dels mapes, la capacitat d'orientació i l'ús de noves tecnologies enfront de les tradicionals.

— Taller «Localitzem»: es desenvolupa dins de l'aula. L'objectiu que persegueix és transmetre que la geografia és l'encarregada de distribuir i d'ordenar el territori, com també de buscar la situació més adequada per a cada activitat. Per tant, com a ciutadans, la geografia ens ha de permetre viure en un territori ordenat i on se'ns ofereixin les màximes facilitats per viure-hi i moure'ns. Mitjançant un plànol de grans dimensions del municipi (aproximadament $2 \times 2$ metres, amb trama urbana, eixos de comunicació, parcs i jardins, etc.), que els estudiants del grau hauran preparat en sessions prèvies, es proposa als alumnes d'ESO que localitzin diferents elements singulars de la ciutat o del poble. Per això, s'han preparat també amb anterioritat diverses icones adhesives corresponents a cadascun d'aquests elements i que caldrà que vagin enganxant sobre el plànol. Alguns d'aquests elements poden ser la zona esportiva, l'Ajuntament, el polígon industrial, l'hospital, les zones d'oci, etc. Finalment, s'anima els estudiants a reflexionar sobre les causes i les conseqüències d'ubicar les diferents activitats en el territori, a més de fer-ne propostes de canvi i de millora, entre unes altres qüestions. 
— Taller "Analitzem»: es desenvolupa dins de l'aula. Els alumnes es divideixen novament en dos grups. L'objectiu principal és examinar els canvis succeïts en el territori municipal, tant a nivell físic com humà, des de mitjan segle $\mathrm{XX}$ fins a l'actualitat. Per això, mentre un grup explora els canvis dels usos del sòl amb l'aplicació web L'ull del temps ${ }^{1}$, l'altre grup porta a terme un joc de memòria amb fotografies actuals $\mathrm{i}$ antigues de zones o d'elements singulars del municipi. Finalment, s'anima els estudiants a reflexionar sobre els canvis succeïts, les causes que els han provocat i els possibles escenaris de futur.

\subsection{Avaluació}

Els universitaris de TMPG són avaluats en relació amb la seva participació en el projecte. Seguint en la línia integradora i transversal de Geoactiva't, i atès que els exalumnes de llicenciatura, de grau i de màster en Formació de Professorat de Secundària són els encarregats de supervisar el treball dels grups, se'ls delega a ells la tasca d'avaluació, que es basa en la puntuació d'1 a 10 d'un seguit d'ítems acordats prèviament amb el professorat de l'assignatura, i que engloben dos grans àmbits: preparació i desenvolupament de la sessió. De les puntuacions dels ítems, se n'obté la nota mitjana per a aquesta part de l'assignatura.

\section{Resultats i valoració}

A partir de la posada en pràctica del projecte Geoactiva't, se n'ha constatat l'èxit didàctic a dos nivells. En primer lloc, incrementa la motivació i la predisposició dels estudiants de secundària a aprendre geografia. Això s'atribueix principalment al fet que els tallers proposats suposen una activitat experimental i manipulativa que situen l'alumne com a actor principal del seu procés d'aprenentatge. A més, la implicació de personal extern al centre de secundària també pot exercir influència en la predisposició dels nois i noies a formar part del projecte. Com a resultat, Geoactiva't va un pas més enllà de l'ensenyament tradicional a l'aula i fa un salt per situar els estudiants d'ESO dins la pell del geògraf professional.

En segon lloc, el projecte apropa els universitaris de grau a la vida quotidiana de la tasca docent, tant pel que fa la planificació fora de l'aula com a l'activitat dins del centre. La docència és, sens dubte, un dels possibles camins professionals per als estudiants dels últims cursos del grau de Geografia. Geoactiva't permet apropar-los a aquesta realitat amb l'objectiu que n'extreguin les seves pròpies conclusions i que valorin si la tasca docent s'ajusta a les seves expectatives personals i professionals. Creiem que, d'aquesta manera, dotem l'alumnat d'un posicionament millor per prendre decisions en aquest sentit.

El plantejament general de la sessió, i per tant també dels tres tallers, es basa en l'ús de múltiples recursos per treballar competències bàsiques diferents. Ara

1. <http://betaserver.icgc.cat/visor/catalunya_ull_del_temps.html>. 
bé, cal entendre el projecte com una eina dinàmica i flexible que cal adaptar a cada context particular i modificar-lo quan convingui. Precisament, un dels seus punts forts és presentar el coneixement geogràfic i la metodologia que empra com quelcom que evoluciona cronologgicament i que es troba en el nostre àmbit quotidià. Sens dubte, el projecte deixa la porta oberta a seguir ampliant aquest coneixement mitjançant els estudis de grau de Geografia i, per tant, actua també com a instrument eficaç de promoció.

D'altra banda, el desenvolupament de les sessions als centres de secundària representa una experiència enriquidora també per a l'àmbit universitari. Els coneixements adquirits gràcies al projecte han permès fer-se una imatge més clara de la percepció que els estudiants d'ESO i el seu professorat tenen de la geografia. Aquesta informació es pot utilitzar per detectar mancances o punts febles on calgui incidir per tal de millorar la docència de la geografia $i$, per extensió, de les ciències socials. Un exemple el constitueix el fet que, contràriament a una de les hipòtesis de partida del projecte, els estudiants de secundària sembla que tinguin més predilecció per orientar-se utilitzant mapes en format paper que no pas digitals. Sens dubte, aquest tipus de valoracions permeten, al mateix temps, reformular el propi projecte a cada edició.

Finalment, cal dir que Geoactiva't aconsegueix que diferents agents vinculats a l'àmbit de l'ensenyament s'hi impliquin i el coordinin. Aquesta visió transversal és necessària per no deslligar el procés educatiu i donar-li coherència i continuïtat en tots els seus àmbits. La participació dels diferents agents, ja siguin els centres d'ESO, els antics estudiants de secundària i de grau o els vigents, esdevé imprescindible per garantir la continuïtat de la iniciativa amb una coordinació total.

\section{Referències bibliogràfiques}

Carretero, Mario (1989). La enseñanza de las Ciencias Sociales. Madrid: Visor.

DELORS, Jaques (1996). «Los cuatro pilares de la educación». A: La educación encierra un tesoro: Informe a la UNESCO de la Comisión internacional sobre la educación para el siglo XXI. Madrid: Santillana / UNESCO, 91-103.

GARCÍA HOZ, Víctor (1996). Enseñanza de las ciencias sociales en educación secundaria. Madrid: Rialp. 